\title{
The Impact of Family Rearing Style on Children's Resilience Under the Background of New Era- Empirical Study Based on North China Electric Power University
}

\author{
Junxiang Wang \\ North China Electric Power University, China \\ 821600776@qq.com
}

\begin{abstract}
Based on the theory of resilience, from the formation and cultivation of the resilience of adolescents in their growing environment, the manifestation of the resilience of their children in different family rearing styles are investigated, and it is find that the resilience of different children caused by different parenting styles has their own characteristics. On the other hand, there are strong commonalities, that is, the development imbalance between the depth and dimension of resilience, and the orientation of family education model. Based on the study of relevant literature, the orientation of cultivating resilience of "one main body, one promotion and three improvement" on the basis of in-depth discussion on how to change the family education mode and realize the improvement of children's resilience are puts forward. It also suggests that the improvement of adolescents 'resilience should be promoted from the perspective of family education content and the improvement of social service path, and the two-way interaction of good family upbringing system should be constructed.
\end{abstract}

Keywords: family education resilience path proposal.

\section{Introduction}

With the rapid development of contemporary Chinese society, profound changes have taken place in China's economy, politics and culture. With the rapid changes in the social background of the new era and the trend of social integration, the way of family education in contemporary China has also undergone tremendous changes. There are more difficulties and challenges in the transitional Chinese society. At the same time, in the small-scale society of family and school, every individual faces the same pressure and adversity as the social people. Almost every day, there are violent assaults, suicides and autism among adolescents in the newspapers. In the critical cognitive period of life, they have little coping strategies when facing difficulties without experience of setbacks. Family planning policy of only one child per family who is spoiled raised up make his psychological endurance few or little. They are unable to solve and face the pressure from unbearable. Therefore, the resilience of adolescent groups can be improved by improving their psychological resilience and physical resilience, so that they can play their own sense of efficacy in the face of problems instead of blindly avoiding and silence. And deal with problems in a positive way, so that their abilities, processes and results can play a role together, so as to reduce or even eliminate the occurrence of evil events of adolescents.

Considering these factors, adolescents' group interaction, family interaction and social interaction at the same time can be the problems that need to be solved urgently. From the perspective of the theory that family education changes can improve the resilience of adolescents, and from the perspective of constructing a complete growth environment for adolescents, the commonness and ways to solve the problem of insufficient resilience of adolescents are explored. That is to promote the relevant proposals to become a basic understanding of the two-way interaction between the state and the family. And which are no longer just staying in the perspective of constructing a complete growth environment at the social policy level of "picking up the missing part to make up for the deficiencies", so as to eliminate the growth dilemma of low resilience of adolescents from the dual dimensions. 


\section{Definition of Core Concepts}

(1) Resilience

Resilience is also called recoverability by Taiwan scholars, resilience by Hong Kong scholars, mental elasticity and tenacity by mainland scholars. It roughly corresponds to the concepts of endurance in difficulty and endurance ability, and refers to the psychological coordination and suitability of a person when he is in a difficult, frustrating and failure situation. when he is facing adversity, can rationally make positive choices and treatment methods; Resilience is a kind of resources and assets, which can lead individuals to know how to deal with adverse conditions in adverse circumstances, so as to produce positive results. People with high resilience are more able to face adversity with a healthy and optimistic attitude. Through learning, they can continuously strengthen and acquire resilience. At this time, the scientific family education is very important and crucial to the acquisition of resilience.

(2) Protective factors of resilience

The protective factors of resilience consist of internal factors and external factors. They coordinate to regulate and mitigate the impact of crisis factors on individuals. As a result, the incidence of problem behaviors is reduced or the rate of successful adaptation is increased. Previous studies generally discussed the intrinsic protective factors of resilience from the perspective of individual factors, and the external protective factors from the perspective of family, school and society.

Internal protective factors: self-awareness plays an important role in resisting adversity: (1). Possessing emotions that reflect pleasant moods and subjective well-being of life satisfaction. (2) having an optimistic and positive attitude, in the face of people and things around the positive and positive understanding. (3) Don't evade difficulties and responsibilities when facing pressure, be brave to challenge oneself and take the initiative to control one's mood.

External factors: resilience refers not only to individual characteristics, but also to some external factors, such as family, school and social support. The greatest factor affecting resilience comes from family support and care. Families can constantly provide encouragement and affirmation, and create trust and love. Encouragement and support among warm families, friendly families, intimate emotions, warm and critical peers, and problem solving skills and autonomy, sense of purpose, critical awareness acquired in learning and life, as well as experience and conscious integration of successful students into development.

(3) EMBU, CD-RISC Scale

This study adopted the Chinese version of EMBU and CD-RISC, which were introduced and revised by Yue Dongmei in the late 1980s. EMBU is a questionnaire compiled by C. Perris, Department of Psychiatry, Umea University, Sweden, in 1980 to evaluate parenting attitudes and behaviors. It is the most commonly used assessment tool for perceiving parenting styles in the world. It has good reliability, validity and structural stability of factors. Yue version of EMBU is more in line with China. The situation and the actual situation of Chinese students. Zhang Jianxin, a psychologist, has made a thorough and meticulous study of this field. He used factor analysis to divide family upbringing into four types: emotional warmth and understanding, severe punishment, refusal and denial and over-protection. Affective warmth and understanding parents are mostly more cordial, and children will actively encourage and help when they do things or encounter difficulties. Punishing harsh mothers can impose many constraints on their children, including details of life. Refusal-denial parents do not care much about their children's difficulties and problems, or deny their children's views and opinions, and force their children to do things according to their own wishes. Overprotective parents ask their children's whereabouts and activities thoroughly and do not give their children the space to move independently.

CD-RISC is a self-measuring scale developed by Kathryn M. Connor and Jonathan R. T. Davidson to test the level of individual psychological resilience. The scale achieved good internal consistency, reliability and validity (Connor \&amp; Davidson, 2003). 
1. Analysis of the Present Situation of Children's resilience Against Adversity in the Context of the New Era

(1) Basic information of the object of study

A total of 330 questionnaires were sent to all grades of North China Electric Power University. 312 valid questionnaires were collected, including 130 boys and 182 girls, 102 freshmen, 76 sophomores, 112 juniors and 22 seniors, living in 176 cities and 136 rural areas.

\begin{tabular}{cccc}
\hline \multicolumn{4}{c}{ Table 1. Basic information of student fathers } \\
\hline \hline items & classification & frequency Effective percentage \\
Education level & Primary school & 30 & 9.6 \\
& Junior middle school & 76 & 24.4 \\
& Senior High School (Secondary Technical School) & 74 & 23.7 \\
& University (College) & 132 & 42.3 \\
occupation & Worker & 102 & 32.7 \\
& farmer & 68 & 21.8 \\
& Intellectual & 82 & 26.3 \\
& cadre & 60 & 19.2 \\
\hline
\end{tabular}

Fathers of students have a high level of education, including 132 College students, 74 high school students, 76 junior high school students and 30 primary school students, including 102 workers, 68 farmers, 82 intellectuals and 60 cadres.

\begin{tabular}{cccc}
\hline & Table 2. Basic information about student mothers & \\
\hline \multirow{2}{*}{ Education level } & classification & frequency Effective percentage \\
& Primary school & 40 & 12.8 \\
& Junior middle school & 106 & 34 \\
& Senior High School (Secondary Technical School) & 70 & 22.4 \\
occupation & University (College) & 96 & 30.8 \\
& Worker & 94 & 30.1 \\
& farmer & 64 & 20.5 \\
& Intellectual & 100 & 32.1 \\
& cadre & 54 & 17.3 \\
\hline
\end{tabular}

The educational level of mothers of students is slightly lower than that of their fathers. There are 96 College students, 70 high school students, 106 junior high school students and 40 primary school students. There are 94 workers, 64 farmers, 100 intellectuals and 54 cadres.

(2) The resilience of Students

Descriptive statistics show that the total score of resilience of student ranges from 41.00 to 100.00 , with an average of $67.96+12.932$.

Table 3. Total score of students 'resilience

$\mathrm{N}$ Minimum value Maximum value mean value standard deviation

$\begin{array}{llllll}\text { Total score } & 312 & 41 & 100 & 67.96 & 12.932\end{array}$

effective N (List state) 312 
The distribution of resilience of students can be investigated from the frequency distribution histogram. From Figure 1, it can be seen that the distribution of students' stress resistance is similar to the normal distribution. Most scores of students are near the mean, and low and high grades are less.

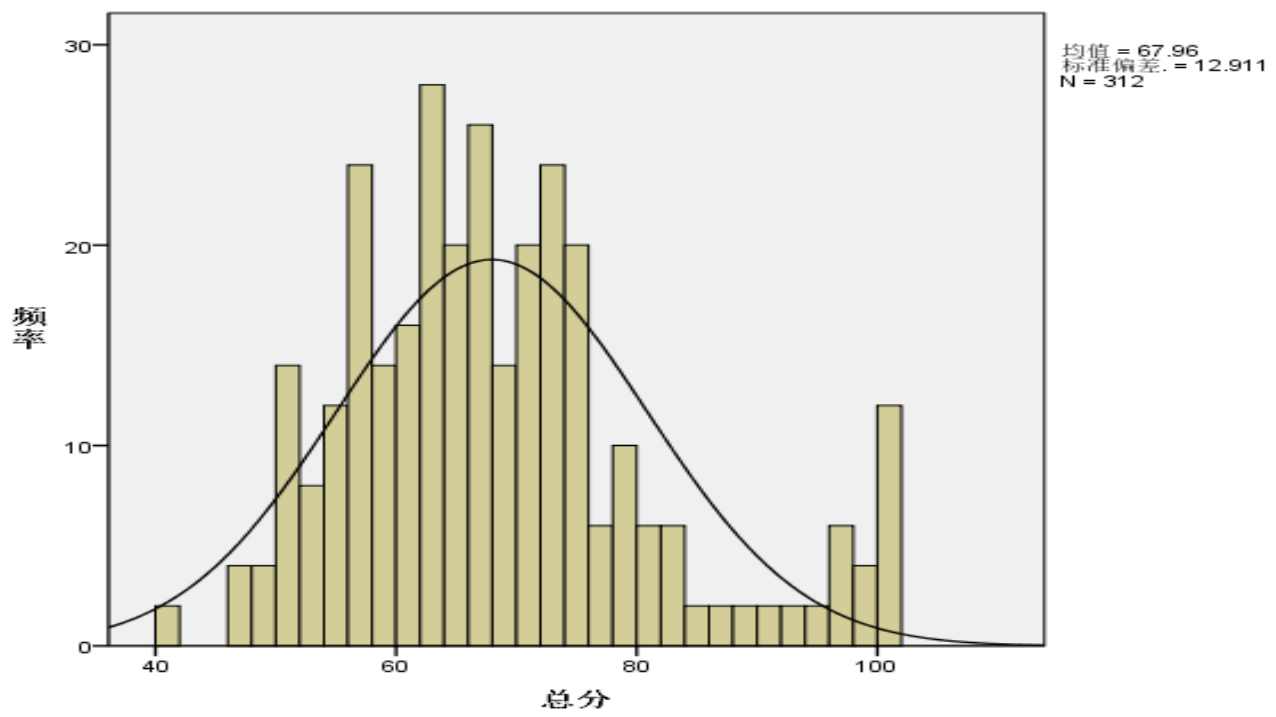

频率 frequency

均值 mean value

标准偏差standard deviation

Figure 1. Distribution of Resilience of Students

(3) Grade assessment of resilience of students

The average and standard deviation are used to evaluate the level of individual resistance accurately. The rules of conversion are as follows: Table 4:

Table 4. Resilience Score Conversion Table

$\begin{array}{ccc}\text { rule } & \text { Original score } & \text { grade } \\ 0 \leq \mathrm{score} \leq \mathrm{M}-2 \mathrm{SD} & 0 \sim 48 & 1 \\ \mathrm{M}-2 \mathrm{SD} \leq \mathrm{score} \leq \mathrm{M}-\mathrm{SD} & 49 \sim 59 & 2 \\ \mathrm{M}-\mathrm{SD} \leq \mathrm{score} \leq \mathrm{M} & 60 \sim 71 & 3 \\ \mathrm{M} \leq \mathrm{score} \leq \mathrm{M}+\mathrm{SD} & 72 \sim 82 & 4 \\ \mathrm{M}+\mathrm{SD} \leq \mathrm{score} \leq \mathrm{M}+2 \mathrm{SD} & 83 \sim 93 & 5 \\ \mathrm{M}+2 \mathrm{SD} \leq \mathrm{score} \leq \mathrm{M}+100 & 94 \sim 100 & 6\end{array}$

Therefore, students 'resilience scores are divided into six grades. The higher the grade, the stronger the resistance. After score conversion, the distribution of resilience is shown in Table 5.

(4) Study on the correlation between students 'resilience and their basic information 
Table 5. Distribution Table of Resilience Level of Students

\begin{tabular}{ccccc}
\hline \hline & & frequency & Effective percentage & Accumulated percentage \\
& 1 & 2 & .6 & .6 \\
& 2 & 42 & 13.5 & 14.1 \\
& 3 & 128 & 41.0 & 55.1 \\
valid & 4 & 94 & 30.1 & 85.3 \\
& 5 & 22 & 7.1 & 92.3 \\
& 6 & 24 & 7.7 & 100.0 \\
\hline
\end{tabular}

(1) Study on the correlation between resilience of students and their basic information

3. Difference Analysis of Gender Factors

Descriptive statistics of resilience of students of different genders were made, and T-test of independent samples was made according to gender factors. The results are shown in tables 6 and 7 below.

Table 6. Resilience of Different Genders

\begin{tabular}{|c|c|c|c|c|c|}
\hline & 1 ,gender & $\mathrm{N}$ & Mean value & Standard deviation & Standard error of the mean value \\
\hline \multirow{2}{*}{ Total score } & male & 130 & 68.52 & 14.353 & 1.780 \\
\hline & female & 182 & 67.55 & 11.879 & 1.245 \\
\hline
\end{tabular}

Table 7. Single factor ANOVA test for stress resilience scores of different genders

\begin{tabular}{|c|c|c|c|c|c|}
\hline & Sum of squares & df & mean square & F & significance \\
\hline between-column & 71.886 & 1 & 71.886 & .430 & .512 \\
Intro- group & 51769.486 & 310 & 166.998 & & \\
Total score & 51841.372 & 311 & & & \\
\hline
\end{tabular}

According to Table 6 and 7, the resistance score of boys is $68.52(+14.353)$, while that of girls is $67.55(+11.879)$, and that of girls is slightly lower than that of boys. From the single factor ANOVA test, sig $>0.05$ indicates that there is no significant difference in stress resistance between boys and girls. 
4. Single factor ANOVA test with grade

Table 8. Single factor ANOVA test for stress resilience scores of different grades

\begin{tabular}{|c|c|c|c|c|c|}
\hline & Sum of squares & df & mean square & F & significance \\
\hline between-column & 7.490 & 3 & 2.497 & 2.170 & .092 \\
Intro- group & 354.305 & 308 & 1.150 & & \\
Total score & 361.795 & 311 & & & \\
\hline
\end{tabular}

Single factor ANOVA test was used to analyze the total score of students 'resilience and grade. The significance was 0.092 more than 0.05 , which did not reach significant statistical significance. This shows that there is no significant difference in resilience among students of different grades. The reason may be that with the increase of age and grade, as a semi-social College student, internal and external abilities have been improved correspondingly, self-determination consciousness is stronger, self-awareness has been improved, sense of goal has been enhanced, communication and cooperation, coping ability has reached a certain level. Therefore, there is no significant difference in the level of resilience among students in grade.

5. Descriptive Statistics of Household Registration Places and Single-factor ANOVA Test

Table 9. Resistance Scores of Different Household Registers

\begin{tabular}{|c|c|c|c|c|c|c|c|c|}
\hline & \multirow{2}{*}{$\mathrm{N}$} & \multirow{2}{*}{$\begin{array}{l}\text { mean } \\
\text { value }\end{array}$} & \multirow{2}{*}{$\begin{array}{l}\text { standard } \\
\text { deviation }\end{array}$} & \multirow{2}{*}{$\begin{array}{l}\text { Standard } \\
\text { error }\end{array}$} & \multicolumn{2}{|c|}{$\begin{array}{c}95 \% \text { confidence interval } \\
\text { of mean }\end{array}$} & \multirow{2}{*}{$\begin{array}{l}\text { Minimum } \\
\text { value }\end{array}$} & \multirow{2}{*}{$\begin{array}{l}\text { maximum } \\
\text { value }\end{array}$} \\
\hline & & & & & lower limit & $\begin{array}{l}\text { Upper } \\
\text { limit }\end{array}$ & & \\
\hline \multirow{3}{*}{$\begin{array}{c}\text { city } \\
\text { Rural area } \\
\text { Total } \\
\text { score }\end{array}$} & 176 & 69.89 & 13.590 & 1.449 & 67.01 & 72.77 & 41 & 100 \\
\hline & 136 & 65.46 & 11.653 & 1.413 & 62.64 & 68.28 & 47 & 100 \\
\hline & 312 & 67.96 & 12.932 & 1.035 & 65.91 & 70.00 & 41 & 100 \\
\hline
\end{tabular}

Table 10. Single factor ANOVA test for stress resilience scores of different household registries

\begin{tabular}{|c|c|c|c|c|c|}
\hline & Sum of squares & $\mathrm{df}$ & mean square & $\mathrm{F}$ & significance \\
\hline between- & 752.955 & 1 & 752.955 & 4.607 & .033 \\
column & 25167.731 & 154 & 163.427 & & \\
Intro- group & 25920.686 & 155 & & & \\
Total score & 2595 & & \\
\hline
\end{tabular}

Descriptive statistics were made on the resistance scores of students from different domiciles, and ANOVA test was used to test the scores. Assuming that there is no significant relationship between household registration and resilience of students, Sig $<0.05$, the hypothesis is not valid, the difference of resilience among students in different household registration areas is very significant, reaching statistical significance. The average resilience of urban students is $69.89(+13.590)$ and that of rural students is $65.46(+11.653)$. The resilience of urban students with excellent conditions is obviously better than that of rural students.

6. The Impact of Family Education on Children's Resilience to Adversity

Family is the primary place for teenagers to grow up. Parents are the enlightening teachers and lifelong teachers for their children. They play an irreplaceable role in the process of teenagers 'growth. Because parents and children have natural blood relationship advantages, parents, as natural educators of adolescents, play a preconceived role in the growth of adolescents. Parents' cultural qualities have a profound and lifelong impact on their children's resilience. 
Table 11. Cross-analysis of Father's Educational Level and Father's Type

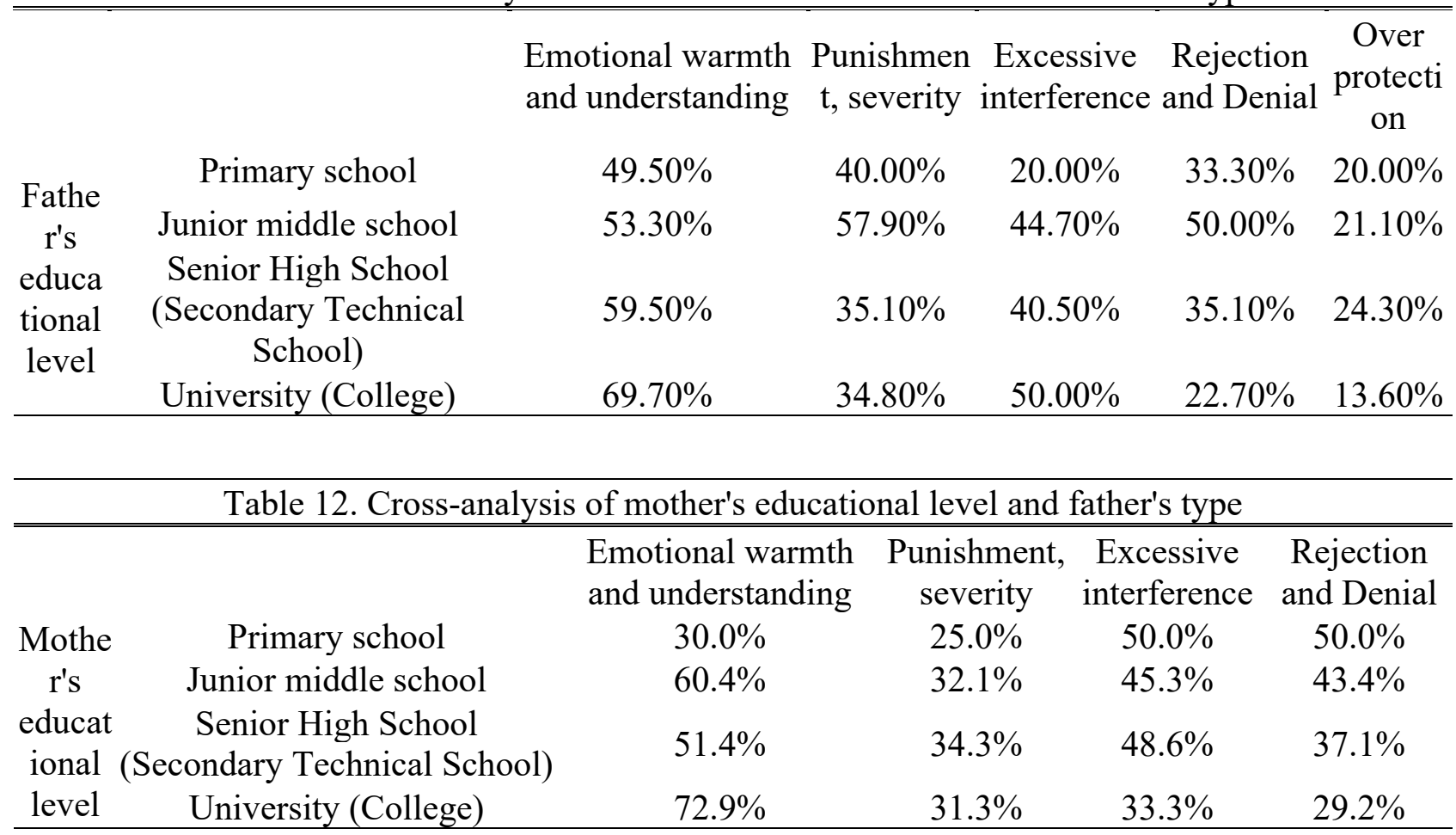

Cross-analysis was made on parents' educational level and parenting style. The study found that parents with higher education tended to adopt a democratic understanding of parenting, while parents with lower education tended to adopt a punishing and strict family upbringing, while fathers with higher education tended to adopt an excessively interfering autocratic family upbringing. To a great extent, parents' cultural accomplishment determines the application of their educational methods. Highly educated parents have strong educational awareness, correct educational concepts and strong educational awareness. Their educational methods tend to be more rational, their educational behaviors are more democratic and independent, their understanding of educational purposes is clearer, and they can accurately grasp the requirements of social development on the moral quality of talents and attach importance to youth. The moral education of adolescents generally chooses the content and form of education suitable for the healthy development of adolescents. Parents' cultural literacy is the premise and basis for parents to educate their children, and plays an important role in the growth of adolescents. 
Table 13. Pearson correlation

\begin{tabular}{|c|c|c|c|c|c|c|}
\hline & $\begin{array}{l}\text { Toug } \\
\text { hness }\end{array}$ & $\begin{array}{l}\text { Compl } \\
\text { iance }\end{array}$ & $\begin{array}{l}\text { Auto } \\
\text { nomy }\end{array}$ & $\begin{array}{c}\text { Social } \\
\text { Boldness }\end{array}$ & $\begin{array}{l}\text { Resource } \\
\text { utilization } \\
\text { rate }\end{array}$ & $\begin{array}{l}\text { Total score of } \\
\text { resilience }\end{array}$ \\
\hline $\begin{array}{l}\text { Emotional warmth and } \\
\text { understanding (father) }\end{array}$ & $\begin{array}{c}.262 * \\
*\end{array}$ & $.300 * *$ & $\begin{array}{c}.293 * \\
*\end{array}$ & $.227 * *$ & $.260 * *$ & $.345 * *$ \\
\hline $\begin{array}{c}\text { Punishment, severity } \\
\text { (father) }\end{array}$ & $\begin{array}{c}-.208 \\
* *\end{array}$ & $\begin{array}{l}-.224 * \\
*\end{array}$ & $\begin{array}{l}-.215 \\
* *\end{array}$ & $-.191 * *$ & $-.120^{*}$ & $-.246^{* *}$ \\
\hline $\begin{array}{l}\text { Excessive interference } \\
\text { (father) }\end{array}$ & 0.018 & -0.053 & 0.027 & 0.008 & -0.023 & -0.005 \\
\hline Rejection, Denial (Father) & $\begin{array}{l}-.159 \\
* *\end{array}$ & $\begin{array}{c}-.196^{*} \\
*\end{array}$ & $\begin{array}{c}-.203 \\
* *\end{array}$ & $-.138^{*}$ & $-.165^{* *}$ & $-.214 * *$ \\
\hline Overprotection (father) & $\begin{array}{c}- \\
0.091\end{array}$ & -0.051 & $\begin{array}{l}-.123 \\
*\end{array}$ & $-.133^{*}$ & $-.159 * *$ & $-.117^{*}$ \\
\hline $\begin{array}{l}\text { Emotional warmth and } \\
\text { understanding (mother) }\end{array}$ & $\begin{array}{c}.274^{*} \\
*\end{array}$ & $.312 * *$ & $\begin{array}{c}.324 * \\
*\end{array}$ & $.227^{* *}$ & $.260 * *$ & $.350 * *$ \\
\hline $\begin{array}{c}\text { Punishment, severity } \\
\text { (mother) }\end{array}$ & 0.089 & 0.016 & 0.02 & 0.046 & 0.014 & 0.046 \\
\hline $\begin{array}{l}\text { Excessive interference } \\
\text { (mother) }\end{array}$ & 0.083 & -0.089 & $\begin{array}{l}-.146 \\
* *\end{array}$ & -0.052 & -0.093 & $-.114^{*}$ \\
\hline Rejection, Denial (Mother) & $\begin{array}{c}- \\
0.111 \\
\end{array}$ & $\begin{array}{c}-.147 * \\
*\end{array}$ & -0.07 & -0.063 & $-.152 * *$ & $-.131 *$ \\
\hline
\end{tabular}

**. Significant correlation was found at the level of. 01 (bilateral).

* Significant correlation was found at 0.05 level (bilateral).

It can be seen from the table that the dimensions of most parental rearing styles are significantly correlated with the five factors of stress resistance $(p<0.01)$. Parents' warm understanding has a positive impact on children's resilience development. Fathers' severe punishment, denial of rejection, over-protection and mother's excessive interference and refusal of denial have a negative impact on children's resilience development.

Parents' understanding and warmth of their children are positively correlated with their children's resilience, adaptability, autonomy, social boldness and resource utilization rate $(p<.01)$. Severe punishment, excessive interference, refusal to deny and excessive protection by parents have some effects on their children's resilience, adaptability, autonomy, social boldness and resource utilization rate. It may be different, but it is negatively correlated in general. The results show that children's resilience level is better in parents and families with warm understanding of their children, while in families with severe punishment, excessive interference, refusal to deny and excessive protection, children's resilience level is worse than that of families with parents' respect and understanding. Parents show affective love, warm trust, understanding and respect for their children, tolerance to their children, enough support and help to their children, and promote their children's resilience level; and often punish their children, and punish their children too severely, and often deny and interfere with their children's resilience water. It has a negative impact.

7. The present situation of children's resilience in the new era

(1) Children have high resilience, but the development of all dimensions of resilience is not balanced.

Resilience of adolescents is relatively high. The average score of overall resilience is 67.96, which is above the middle level. This shows that most teenagers have the ability of resisting adversity and recovering to good adaptation when facing difficulties. The development of various dimensions of resilience of adolescents is not balanced, the development of mental strength and social competence is better, while the development of cognitive ability and positive emotional feelings is weaker. Because the role of resilience requires the interaction of various factors within the individual, which 
means that in order to enhance the resilience of adolescents, we should take the improvement of their cognitive ability and positive emotional feelings as a breakthrough and focus, and strengthen their self-awareness and environmental insight through various ways and means to improve resilience of adolescents, and positive emotional feelings such as sense of security and sense of belonging.

(2) There are differences in parenting styles between fathers and mothers.

Research shows that there are differences between the parenting behavior of fathers and that of mothers. Fathers punish their children more severely than mothers, but their emotional warmth, excessive interference and refusal to deny their children are more than mothers. Father's upbringing affects children's sense of achievement. Achievers generally have close relationships with their fathers. In addition, father's support affects mother's emotions, self-confidence, motivation and parent-child relationship. The understanding of parents and support promote their children's ability to analyze and deal with things. They respond appropriately to events and have less emotional distress. On the contrary, punishment and over-protection are not conducive to the development of their children's ability to analyze and deal with things, and will have a negative impact on their children's social behavior, resulting in their children's negative self-knots. Construct, hinder the healthy development of their psychology. In the face of life troubles, we cannot analyze and solve them positively and actively, but avoid or overreact to them, resulting in emotional distress. Father's severe punishment and refusal to deny easily make children fear and avoid their fathers. Especially for girls, this fear is more likely to make them have problem behavior and psychology, and make them form unhealthy psychology. Parents' full emotional warmth and understanding are conducive to the healthy development of individual psychology. Therefore, in family education, there should be both warm maternal love and father's emotional understanding and care. Children feel that their parents' care, tolerance and warmth will promote their children to acquire a sense of achievement, form self-esteem and self-confidence, and promote their independent reasoning and judgment ability and the development of their mental health.

(3) The influence of different parenting styles on children's resilience is quite different.

Family upbringing is a summary of the characteristics of parents' various upbringing behaviors. Due to the different life experiences, cultural accomplishments, ideological positions, personality characteristics and family backgrounds of family members, family styles are different. Parents have relatively stable behavior styles in educating their children's speech, behavior and attitudes. The formation of women's resistance to adversity has an important impact. Higher educated parents tend to adopt a democratic understanding of the way of upbringing; lower educated parents tend to adopt punishment, strict family upbringing; and in the table, higher educated fathers adopt excessive interference in autocratic family upbringing.

Parental rearing style plays a very important role in enhancing the resilience of adolescents. Teenagers exert educational influence on them by accepting parental rearing style, inherit and acquire social values and traditional behavior habits, and make psychological preparations for future development. For adolescents, because mothers take more care of and educate them, the impact of mothers' educational methods on children's resilience is particularly important. According to the research results of psychologists in the East and the West, we know that parents 'educational level is the key factor affecting their choice of different educational methods. This reminds us that we should improve parents' cultural accomplishment, strengthen the research and intervention on parents' educational methods, especially mothers' so as to provide children with a healthy and positive attitude. The physical and mental development environment makes the teenagers' resilience improve effectively, and lays a good foundation for the socialization development of the later stages.

8. Countermeasures and suggestions

(1) Enriching the content of family upbringing

Taking adolescents as the foundation, focusing on pre-investigation and analysis, providing different and pluralistic cases of family upbringing model to meet the diversified needs of adolescents. In addition, providing special services to those adolescents who are in difficulties or have low resilience level, focusing on the unique needs of family upbringing modes, From the perspective of cognitive ability, emotional support and problem-solving guidance, we can help adolescents get more 
constructive guidance from their parents to cope with adversity, and solve the problems that need to be improved in the family. Parents and children are both parents and children for the first time. Both of them should constantly learn to be better parents and children. The way of family upbringing is parents' attitude and feelings towards their children. It reflects the nature of parent-child interaction and has cross-situational stability and clear purpose of upbringing.

(2) Perfecting the Path of Social Service

Teenagers are not passive recipients of family education. They have creative ability and unique thinking. They are an important resource for social construction. Therefore, it is necessary to organize social organizations to conduct family education lectures for parents to guide them to educate and inspire their children in the correct way of family upbringing, and constantly tap the youth. The intrinsic potential of adolescents and the promotion of adolescent participation are not only conducive to better quality services for adolescents, but also conducive to the overall growth of adolescents.

(3) Enhancing the ability of adolescents to absorb the essence of family education

Although parents fulfill their responsibilities as parents, the essence of these educational models is only a potential support for young people. To enable potential support to become reality support, we must enhance the ability of young people to improve their antagonism. This is also a manifestation of adolescents' ability to cope with adversity. For this reason, it is not only the responsibility of the family but also the responsibility of the society to carry out lectures on the cultivation of resilience for teenagers and to carry out modern psychological construction model of resistance to setbacks.

The way of family upbringing is shown in the family emotional atmosphere. Adolescents' attitudes, feelings, perceptions and general behaviors may reflect the dominant emotional atmosphere in the family. If children are in a harmonious, happy, tense and orderly family, and get a sense of security from their family, they will be able to adapt smoothly to the requirements of life and solve problems encountered. If the family is characterized by punishment, chaos and excessive severity, and has a negative color, the possibility of children's problems is relatively high, which depends on the parents' emotions, ideological and cultural accomplishments and scientific educational concepts and attitudes.

(4) Respect and understanding for children

Parents must respect and understand their children when they talk to them. Parents' respect for their children means trust and encouragement, which helps them form positive self-concept and healthy personality. Only by respecting the equal communication between children and children can we establish a good trust relationship with children and open channels for family emotional communication, so as to better understand parents and children. To be friends with your children, you must also understand them. We should stand in the perspective of children, see with the eyes of the parties, listen with the ears of the parties, experience with the hearts of the parties, and put ourselves in a position to understand their troubles and pains. When children have problems, parents do not listen, do not communicate, ignore their children's feelings, blindly scold, will cause greater harm to children. Children are eager to respect and be independent. They want their parents to treat them as adults and treat them equally. This requires parents to change their roles and educational concepts, change the dominant and commanding one-way education, and should be equal and exploratory twoway education. Respect and understanding of children are more conducive to children's healthy psychology and mentality, can also improve the sense of resilience, and guide them to develop a correct attitude and establish their own resilience mechanism.

(5) Parents should have a sense of frustration in Education

It is very important for children to keep a positive attitude towards life when facing difficulties. Not letting children suffer hardships is not giving them happiness. To a certain extent, frustration can also exercise children. Only when children get out of difficulties and setbacks can they really realize what happiness is, because happiness is the spiritual pleasure they can get after overcoming difficulties. If parents always put their children under their own wings to protect them from injury and failure, they will never learn how to bear the blow alone when it comes. Parents should restrain the impulse of "trying to help their children" and give them a chance to "encounter" setbacks. 
(6) Parents should guide their children to enhance their resilience

The role of parents should always be a guide in the whole process from dependence to independence and from childishness to maturity. Parents should teach their children the common sense of life and the truth of life, guide them to open their own doors to life, distinguish right from wrong in life, and understand the true meaning of life. Strong resilience helps to cultivate children's courage to face setbacks, difficulties and failures, so that children can grow up smoothly in a difficult environment.

\section{Conclusion}

In today's society, the issue of mental health has become the focus of public attention, and the problem of children's resilience has been paid more and more attention. Family is the first environment for children to grow up. The influence of parental rearing style on children's resilience is particularly important. It not only plays an important role in improving children's interpersonal communication ability, but also affects the development of children's resilience level together with their interpersonal communication ability. Therefore, in life, we should not only assume the responsibility of raising children, but also pay attention to education. At the same time, we should strengthen our own quality and grow up with our children. Secondly, children contact more friends and classmates in daily life. Peer groups are the most easily used resources around children. We should pay attention to the communication and communication with students, and improve our interpersonal skills and skills in practice. Expand the influence of student groups such as associations, attract like-minded partners, and give children more opportunities to grow up and learn together. In addition, we should carry out a series of special education on resilience, popularize knowledge about resilience for children, raise their awareness of resilience, guide them to develop correct attitudes and establish their own resilience mechanism. In the process of student education and management, we consciously pay attention to the cultivation of students' comprehensive quality, especially resistance, and establish an effective social support system.

\section{References}

[1]. Vulnerability and resilience: A study of high-risk adolescents. Luther, S.S. Child Development. 1991.

[2]. Tian Guoxiu, Zeng Jing. Concern about Resistance: New Trends in Social Work Theory and Practice [J]. Journal of China Youth Political College, 2007 (01): 130-133.

[3]. Xiong Yuanlai, Zhu Panlin, Zhang Liping. Current situation of adolescent resilience and its training countermeasures [J]. Social Work, 2012 (05): 31-33+50.

[4]. Xia Limin. An overview of the research on family upbringing and children's socialization [J]. Journal of Shandong Normal University (Social Science Edition), 1994 (05): 64-67.

[5]. The Strengths Perspective in Social Work Practice. Dennis Saleebey, D. 2002.

[6]. Creating a future: A study of resilience in suicidal Female adolescents. Robin. D Everall, K. Jessica, Altrows, and Barbara L pauson. Journal of Counseling \&amp; development. 2006.

[7]. Anboxin. The relationship between parenting style, parent-child communication and adolescents'social adaptation [D]. Shaanxi Normal University, 2004.

[8]. Xu Hui, Zhang Jianxin, Zhang Meiling. A review of the impact of family upbringing on children's socialization development [J]. Psychological Science, 2008 (04): 940-942+959.

[9]. Cui Zhe, Zhang Jianxin. The relationship between family upbringing patterns and coping styles of middle school students and their mental health [J]. Chinese Journal of Clinical Psychology, 2005 (02): 180-182. 